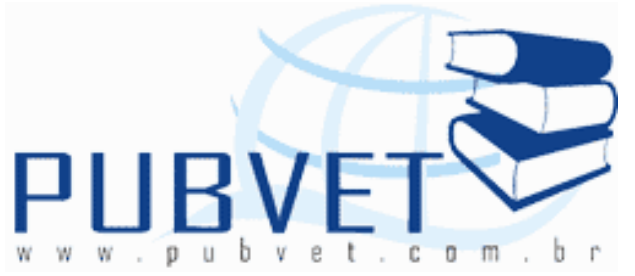

PUBVET, Publicações em Medicina Veterinária e Zootecnia.

\title{
Desempenho produtivo e reprodutivo de um rebanho Guzerá leiteiro
}

Diego de Paiva Borges ${ }^{1}$, Mara Regina Bueno de Mattos Nascimento ${ }^{2}$, Vitória Maria Simioni ${ }^{2}$, Paula Borges Vieira ${ }^{3}$, Carolina Cardoso Nagib Nascimento ${ }^{3}$

${ }^{1}$ Acadêmico da Faculdade de Medicina Veterinária, Universidade Federal de Uberlândia.

${ }^{2}$ Profa. Dra. da Faculdade de Medicina Veterinária, Universidade Federal de Uberlândia.

${ }^{3}$ Mestranda em Ciências Veterinárias da Faculdade de Medicina Veterinária, Universidade Federal de Uberlândia.

\section{Resumo}

Avaliou-se o desempenho reprodutivo e produtivo de um rebanho Guzerá leiteiro no Município de Uberlândia - Minas Gerais. Foram analisadas as características de: idade à primeira concepção; idade ao primeiro parto; período de gestação; período de serviço; intervalo de partos; duração de lactação; período de descanso do úbere; produção de leite por lactação; peso ao nascer; número de serviços por concepção e porcentagem de mortalidade de bezerros. As médias de idade à primeira concepção e ao primeiro parto mostraram-se tardias por práticas inadequadas de manejo, principalmente nutricional e reprodutivo. A imprecisão na detecção de cios para IA pode ter contribuído para o retardamento destas idades. O período de gestação mostrou-se dentro do esperado, visto ser uma característica de baixa variabilidade fenotípica. 0 período de serviço médio mostrou-se acima 
BORGES, D.P. et al. Desempenho produtivo e reprodutivo de um rebanho Guzerá leiteiro. PUBVET, Londrina, V. 5, N. 4, Ed. 151, Art. 1017, 2011.

do considerado ideal para se obter intervalo médio entre partos em torno de doze meses. O intervalo de partos revelou-se comprometido pelo período de serviço elevado. A duração média da lactação mostrou-se dentro de valores normalmente citados na literatura. O período médio de descanso do úbere mostrou-se muito acima do normalmente recomendado numa eficiente exploração leiteira. A média de produção de leite por lactação mostrou-se aquém das citadas na literatura consultada. $O$ peso ao nascer, o número de serviços por concepção e a porcentagem de mortalidade de bezerros mostraram-se favoráveis de acordo com a literatura consultada.

Palavras-chave: Bovino, índices zootécnicos, intervalo de partos, produção de leite.

\title{
Productive and reproductive performance of dairy cattle Guzerath
}

\begin{abstract}
Evaluated the reproductive and productive performance of a dairy herd Guzerath in Uberlândia - MG. Were analyzed: age at first insemination, age at first birth, gestation period, period of service, calving interval, lactation length, dry period of the udder, milk yield per lactation, birth weight, and number of services per conception and percentage of calf mortality. The average age at first insemination and calving showed up late for practices, inadequate management, especially nutrition and reproductive systems. The imprecision in the detection of estrus may have contributed to the delay of these ages. The gestation period was found to be within expectations, since it is a characteristic of low phenotypic variability. The average service period was found to be above what is considered ideal to obtain mean calving interval of around twelve months. Calving interval proved to be compromised by the high period of service. The average lactation period was found to be within the range normally found in the literature. The mean dry period of the udder was found to be well above the normally recommended to efficient dairy farm. The average milk yield per lactation was found to be
\end{abstract}


BORGES, D.P. et al. Desempenho produtivo e reprodutivo de um rebanho Guzerá leiteiro. PUBVET, Londrina, V. 5, N. 4, Ed. 151, Art. 1017, 2011.

lower than those cited in the literature. Birth weight and number of services per conception and mortality of calves were in favor according to the literature.

Keywords: Cattle, performance index, calving interval, milk production.

\section{INTRODUÇÃO}

O Brasil possui o segundo maior rebanho bovino do mundo, porém apresenta baixos índices produtivos e reprodutivos e, em conseqüência, baixa produtividade. Com um rebanho formado, principalmente, por animais zebuínos e seus mestiços, a exploração leiteira é caracterizada pela baixa utilização de insumos, com os animais mantidos em pastagens de baixo valor nutritivo (FONSECA, 2000).

A pecuária de leite no Brasil vem passando nos últimos anos por profundas modificações estruturais que condicionaram mudanças na sua gestão técnica e econômica dentro do sistema de produção de leite que deve ser sustentável ambiental e economicamente (RANGEL et al., 2008).

Os registros zootécnicos ou escrituração zootécnica constituem instrumento fundamental para que o produtor dimensione a eficiência técnica do sistema e identifique os pontos de estrangulamento. Permitem os avanços nos índices de produtividade de tal forma que o esforço administrativo e a introdução de tecnologia sejam relevantes no sentido de promover a melhoria do sistema de produção. Assim, a análise e avaliação constantes de dados compõem o objetivo principal dos registros. Existem vários fatores indispensáveis para o estabelecimento e eficiência desses registros. O primeiro deles é a identificação correta dos animais. Depois, o estabelecimento de um bom sistema de escrituração e, finalmente, avaliação constante dos animais obtidos.

A escrituração zootécnica pode ser feita de maneira manual ou informatizada. Na manual, o produtor utiliza fichas individuais para registro dos dados. Já na informatizada, essas fichas estão contidas em programas 
BORGES, D.P. et al. Desempenho produtivo e reprodutivo de um rebanho Guzerá leiteiro. PUBVET, Londrina, V. 5, N. 4, Ed. 151, Art. 1017, 2011.

específicos de computador. Os índices obtidos com a escrituração zootécnica permitirão um gerenciamento eficiente do rebanho. Isto porque proporcionará conhecer cada um dos animais; identificar aqueles mais produtivos; diagnosticar com rapidez, possíveis problemas; observar o histórico reprodutivo dos animais, etc. Portanto, todas essas vantagens culminarão como uma excelente ferramenta de auxílio à seleção e descarte dos animais (LÔBO, 2003).

Dessa forma, utilizando-se de escrituração zootécnica manual objetivou-se com este trabalho avaliar estatísticas descritivas de algumas características produtivas e reprodutivas de um rebanho bovino leiteiro da raça Guzerá.

\section{REVISÃO DE LITERATURA}

\subsection{Raça Guzerá}

A origem dos bovinos da raça Guzerá é a região pré-desértica de kutch, em Gujarat, sequenciado ao norte pelo deserto de Thar e pelo deserto de Sind. No Brasil, o Guzerá está espalhado por várias regiões, mas é notória sua presença na região nordestina, onde foi a única raça que sobreviveu, produtivamente, durante os cinco anos consecutivos de seca (1978-1983), além de ter enfrentado também outras secas históricas de 1945 e 1952. A raça foi trazida da Índia, na década de 1870, pelo Barão de Duas Barras, logo dominando a pecuária nos cafezais fluminenses. Surgia como solução para arrastar os pesados carroções e até vagões para transporte de café, nas íngremes montanhas, e também para produzir leite e carne. O Guzerá é de dupla aptidão, com algumas linhagens definidas para leite e a maioria do gado selecionada para carne. Mesmo as linhagens de leite são de grande porte (O Guzerá). 
BORGES, D.P. et al. Desempenho produtivo e reprodutivo de um rebanho Guzerá leiteiro.

PUBVET, Londrina, V. 5, N. 4, Ed. 151, Art. 1017, 2011.

\subsection{Idade à Primeira Concepção}

Idade à primeira concepção constitui importante parâmetro tanto na avaliação do comportamento reprodutivo e de crescimento, quanto das condições de manejo nutricional. A precocidade a esta idade induz à vida útil mais longa com reflexos evidentes na intensidade seletiva a ser aplicada e no ganho genético a ser obtido (PEREIRA, 2008).

Segundo Rodriguez e Cruz (2003), para que as novilhas possam expressar todo seu potencial reprodutivo é necessário que cresçam adequadamente para que uma considerável porcentagem tenha ciclo estral normal e uma boa taxa de concepção. Períodos de escassez de alimentos ocasionam severos efeitos no retardo da concepção. Conforme Marques (2005), o plano de alimentação a ser adotado no sistema de cria e recria das novilhas será aquele onde permita que elas atinjam o peso para cobrição o mais rápido possível. Há escassez de informações na literatura sobre a idade à primeira concepção em raças Zebus. Balieiro (1976 apud PEREIRA, 2008)

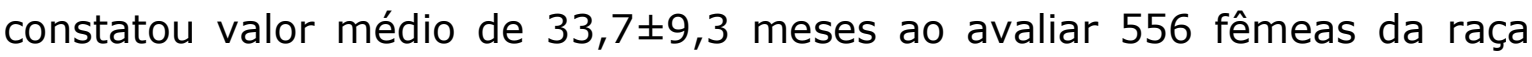
Guzerá.

\subsection{Idade ao Primeiro Parto}

A idade ao primeiro parto é influenciada por vários fatores. Entre eles, taxa de crescimento pré e pós-desmama, puberdade, manifestação do primeiro cio fértil, concepção, gestação, manejo sanitário e alimentar e parição. A idade ao primeiro parto precoce aumenta a produção vitalícia dos animais e, conseqüentemente, aumenta a lucratividade da atividade leiteira, contribuindo para aumentar a intensidade de seleção a ser aplicada refletindo nos ganhos genéticos a serem alcançados (PEREIRA, 2008).

Dados da literatura consultada, apresentados na Tabela 1, mostram idades ao primeiro parto na raça Guzerá oscilando entre 37,50 e 47,00 meses. 
BORGES, D.P. et al. Desempenho produtivo e reprodutivo de um rebanho Guzerá leiteiro.

PUBVET, Londrina, V. 5, N. 4, Ed. 151, Art. 1017, 2011.

Tabela 1 - Número de Observações (N), Médias \pm Desvios-Padrão $(\bar{x} \pm \mathrm{s})$ envolvendo idade ao primeiro parto (meses) na raça Guzerá no Brasil, segundo diferentes autores.

\begin{tabular}{lcl}
\hline Autores & $\mathrm{N}$ & \multicolumn{1}{c}{$(\bar{x} \pm \mathrm{s})$} \\
\hline Carneiro et. al. (1958) & 37 & 46,40 \\
Pires et. al. ( 1967) & 131 & 46,9 \\
Silva et. al. (1971) & 184 & $46,70 \pm 0,50$ \\
Silva et. al. (1971) & 45 & $37,50 \pm 0,76$ \\
Villares (1972) & 28 & 45,80 \\
Gómez Sarmiento (1975) & 148 & 47,00 \\
Andrade et. al. (1977) & 80 & $46,00 \pm 0,82$ \\
Pires et. al. (1977) & 71 & $44,11 \pm 0,60$ \\
Mariz e Oliveira (1983) & 142 & $40,72 \pm 0,84$ \\
Miranda et. al. (1986) & 256 & $38,14 \pm 0,79$ \\
Duarte Ortuňo et. al. (1988) & 56 & $41,49 \pm 1,08$ \\
Embrapa-CNPGL (1982) & 228 & 43,50 \\
Bastos et. al. (1992) & 420 & 39,31
\end{tabular}

Fonte: PEREIRA (2008).

\subsection{Período de Gestação}

Período de gestação consiste no intervalo de tempo transcorrido entre a data de concepção e a data de parição. Destaca-se que a data da concepção é admitida como a do último serviço, uma vez que o dia exato da concepção não é conhecido. Desta forma, o período de gestação é avaliado pela diferença, em dias ou em meses, entre a data do último serviço que resultou em prenhez e a data do parto (PEREIRA, 2008). Conforme estudos realizados por Villares et. al. (1949), na raça Guzerá, o período de gestação obtido foi de $291,9 \pm 7,7$ dias. 
BORGES, D.P. et al. Desempenho produtivo e reprodutivo de um rebanho Guzerá leiteiro.

PUBVET, Londrina, V. 5, N. 4, Ed. 151, Art. 1017, 2011.

\subsection{Período de Serviço}

Período de serviço refere-se ao intervalo decorrido entre o parto e a próxima concepção fértil. Compõe-se do tempo mínimo para que ocorra a involução uterina e renovação das células das glândulas mamárias (MARQUES, 2005). Estima-se pela diferença entre as datas do parto e da próxima concepção fértil. Segundo Pereira (2008), o período de serviço é um dos principais indicadores de eficiência reprodutiva. Isto porque alterações neste parâmetro influenciam diretamente o intervalo de partos. Rangel et. al. (2009) e Bacalhau et al. (1994) encontraram período de serviço médio na

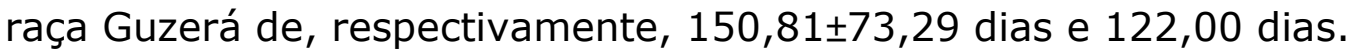

\subsection{Intervalo de Partos}

Intervalo de partos, segundo Andrade (1999) é o tempo entre duas parições consecutivas de uma mesma fêmea. Portanto, é dividido em período de gestação e período de serviço. Como o período de gestação é mais ou menos constante, dentro de certos limites, resta então o período de serviço, onde se poderá interferir para diminuir o intervalo de partos. Sua magnitude determina o número de crias que a vaca produzirá durante sua vida útil, fornecendo uma idéia aproximada da regularidade reprodutiva.

Este parâmetro é reconhecido como um caráter importante na avaliação do comportamento reprodutivo de um rebanho sendo resultado da ação conjunta da herança e do meio. É dependente de práticas de manejo e de fatores patológicos e fisiológicos, segundo Mattos e Rosa (1984 apud GRESSLER, 1998). Semelhantemente, Ferreira (2009) afirmou que o intervalo de partos é altamente influenciado pelo ambiente, sendo, portanto, possível a obtenção de menores valores com mudanças no manejo, como detecção mais acurada de estros e suplementação mineral.

Dados da literatura consultada, apresentados na Tabela 2, mostram intervalos de partos na raça Guzerá oscilando entre 424,93 e 579,44 dias. 
BORGES, D.P. et al. Desempenho produtivo e reprodutivo de um rebanho Guzerá leiteiro.

PUBVET, Londrina, V. 5, N. 4, Ed. 151, Art. 1017, 2011.

Tabela 2 - Número de Observações (N), Médias \pm Desvios-Padrão $(\bar{x} \pm s)$ envolvendo intervalo de partos (dias) na raça Guzerá no Brasil, segundo diferentes autores.

\begin{tabular}{lcc}
\hline Autores & N & $(\bar{x} \pm$ s) \\
\hline Carneiro et. al. (1956) & 129 & 549,03 \\
Carneiro et. al. (1958) & 128 & 564,23 \\
Carneiro et. al. (1960/61) & 5158 & 579,44 \\
Domingues (1966) & $\ldots$ & 458,99 \\
Pires et al. (1967) & 302 & 511,31 \\
Silva (1971) & 337 & $545,90 \pm 7,20$ \\
Silva (1971) & 329 & $451,50 \pm 6,20$ \\
Villares (1972) & $\ldots$ & 480,59 \\
Torres e Pinheiro (1974) & 192 & 466,90 \\
Tundisi et. al. (1974) & 372 & 444,08 \\
Balieiro (1976) & 2158 & $516,00 \pm 2,81$ \\
Gómez Sarmiento (1976) & $\ldots$ & 515,87 \\
Pires et. al. (1977) & 109 & 448,35 \\
Campos et. al. (1983) & 742 & 486,97 \\
Mariz e Oliveira (1983) & 290 & 489,41 \\
Miranda et. al. (1986) & 946 & 448,04 \\
Embrapa (1991) & $\ldots$ & 424,93
\end{tabular}

Fonte: PEREIRA (2008).

Nota: três pontos (...) indicam dado desconhecido.

\subsection{Duração da Lactação}

Duração da lactação é calculada pelo intervalo de tempo decorrido entre as datas do parto e de secagem das vacas. É muito importante na avaliação do desempenho reprodutivo do gado leiteiro e do ponto de vista econômico, por estar relacionada com a produção de leite. 
BORGES, D.P. et al. Desempenho produtivo e reprodutivo de um rebanho Guzerá leiteiro. PUBVET, Londrina, V. 5, N. 4, Ed. 151, Art. 1017, 2011.

Estudos conduzidos por Barbosa e Pereira (1983), Bacalhau et al. (1990) e Bacalhau et al. (1994) evidenciaram duração da lactação de $272,00,167,80$ e 273 dias, respectivamente, para a raça Guzerá.

\subsection{Período de Descanso do Úbere}

Conforme Krug et al. (1980), período de descanso do úbere, também conhecido como período seco, corresponde aos 60 dias do período do préparto. Um período seco de 60 dias vem, há muito tempo, sendo adotado pela maioria dos criadores de gado leiteiro a fim de permitir, entre uma lactação e outra, a regeneração dos tecidos epiteliais desgastados da glândula mamária, acumular colostro e assegurar o desenvolvimento do feto, e por último completar as reservas corporais, quando estas ainda não ocorreram. Os motivos que levam à adoção de um período seco reduzido são: possível incremento na produção de leite, na lactação em questão, pelo aumento do número de dias em que a vaca é ordenhada; simplificação do manejo de vacas secas; diminuição de desordens metabólicas; alívio na superlotação das instalações para vacas secas. Tradicionalmente, o período de descanso do úbere foi definido como tendo três estágios funcionais, involução ativa (regressão dos tecidos secretores), período de descanso; lactogênese (retorno da capacidade de síntese do tecido secretor). $\mathrm{Na}$ literatura consultada não foram encontradas citações quanto a duração do período de descanso do úbere na raça Guzerá.

\subsection{Produção de Leite}

A produção de leite é utilizada tradicionalmente como o mais importante parâmetro em programas de seleção de rebanhos leiteiros (GUIMARÃES et al., 2002).

Bacalhau et al. (1994) constataram média de produção de leite de 2314 kg em 273 dias de lactação ao avaliarem 72 vacas da raça Guzerá. 
BORGES, D.P. et al. Desempenho produtivo e reprodutivo de um rebanho Guzerá leiteiro.

PUBVET, Londrina, V. 5, N. 4, Ed. 151, Art. 1017, 2011.

Cobuci et al. (2000) ao analisarem registros de 1130 lactações de 583 vacas da raça Guzerá constataram média de produção de leite por lactação (período médio de 290 dias) de 2359 kg, com coeficiente de variação de $29,51 \%$.

\subsection{Peso ao Nascer}

O peso ao nascer é a primeira informação após o nascimento do animal, indicando seu vigor e desenvolvimento pré-natal, fortemente influenciado por fatores ambientais que incidem na matriz, antes e durante a gestação, e pelo próprio período de gestação. Esta medida é importante para acompanhar o desenvolvimento ponderal do animal, além de ser utilizada, eventualmente, para ajustar pesos nas idades padrão posteriores (LÔBO, 1996). Estimativa de peso ao nascer médio de $31,76 \pm 0,51 \mathrm{~kg}$ e de $29,74 \mathrm{~kg}$ foram citadas, respectivamente por Bacalhau et al. (1992) e por Pelicioni et al. (2003).

\subsection{Número de Serviço por Concepção}

O número de serviço por concepção é um critério útil em rebanhos onde a inseminação artificial é praticada. Segundo Pereira (2008), este critério de avaliação da fertilidade tem pouca utilidade prática já que o uso da inseminação no Brasil atinge um percentual irrisório. Além desta limitação, esse critério exclui as novilhas e vacas que falham em conceber, pois considera apenas o número de serviços efetuados por concepção com sucesso. No entanto, nas propriedades que utilizam inseminação artificial, este índice poderá auxiliar na avaliação do desempenho reprodutivo e econômico. Haja vista que seu aumento poderá estar relacionado a vários fatores como, fertilidade dos animais, manejo, alimentação, sanidade, habilidade do inseminador e qualidade do sêmen. 
BORGES, D.P. et al. Desempenho produtivo e reprodutivo de um rebanho Guzerá leiteiro.

PUBVET, Londrina, V. 5, N. 4, Ed. 151, Art. 1017, 2011.

Segundo Rawson (1986) valores inferiores a 1,8 são desejáveis, porém as metas visam atingir média de 1,4 a 1,6 serviços/concepção refletindo assim, a excelente fertilidade dos animais e um eficiente processo de inseminação artificial.

\subsection{Mortalidade de Bezerros}

A mortalidade pós-natal, principalmente na fase de aleitamento é geralmente alta. Admiti-se mortalidade média de $15 \%$ durante a fase de aleitamento e de $5 \%$ na fase pós desmama. É inegável a precariedade dos cuidados higiênico-sanitários na quase totalidade do rebanho nacional. Com índices tão elevados, as reformas dos plantéis ficam seriamente comprometidas, dada à associação do binômio alta mortalidade e baixa fertilidade, com reflexos óbvios sobre 0 melhoramento genético das populações (PEREIRA, 2008).

\section{MATERIAL E MÉTODOS}

\subsection{Local e Animais}

Este estudo foi realizado a partir de informações provenientes do controle zootécnico manual implantado na Fazenda Mara Lúcia, localizada no município de Uberlândia - Minas Gerais com dados produtivos e reprodutivos de 70 fêmeas da raça Guzerá no período de 1987 a 2009. A altitude média na propriedade é de 800 metros. O clima predominante é do tipo tropical chuvoso, comum no Brasil central, caracterizado por verão chuvoso (outubro a março) com temperatura média de $22^{\circ} \mathrm{C}$ e, inverno seco (abril a setembro) com temperatura média de $18^{\circ} \mathrm{C}$ (CORRÊA; SANTOS, CARVALHO, 2004). O período seco apresenta aproximadamente $60 \mathrm{~mm}$ de precipitação pluvial e o chuvoso $96 \%$ da precipitação anual que é de 1500 a $1600 \mathrm{~mm}$. 
BORGES, D.P. et al. Desempenho produtivo e reprodutivo de um rebanho Guzerá leiteiro. PUBVET, Londrina, V. 5, N. 4, Ed. 151, Art. 1017, 2011.

A fazenda possui 720 ha. sendo a pastagem constituída de braquiária (Brachiaria decumbens, B. humidicola e B. brizantha), capim jaraguá (Hiparrhenia ruffa), capim sempre verde (Panicum maximun Jacq. Variedade gond loides Doell), grama estrela africana (Cynodon plectostachyus) e grama coast-cross (Cynodon dactilon cv. coast-cross).

A propriedade possui um curral de manejo contendo embarcadouro, brete, tronco e balança, além da sala de espera e de ordenha.

\subsection{Manejo Geral dos Animais}

Os bezerros foram pesados ao nascer e mantidos em piquetes separados, sendo amamentados após a ordenha sem suplementação alimentar.

As matrizes foram ordenhadas mecanicamente duas vezes ao dia, às $05 \mathrm{~h} 30 \mathrm{~min}$ e às $15 \mathrm{~h} 00 \mathrm{~min}$. O controle leiteiro foi realizado quinzenalmente.

O manejo alimentar dos animais baseou-se em regime de pastagem e sal mineral. Na época de seca os animais receberam suplementação à base de silagem de milho.

Os animais eram divididos em piquetes de acordo com sua faixa etária para maior eficácia de manejo. Encontrava-se próximo ao curral um piquete maternidade para as vacas em gestação e paridas.

\subsection{Manejo Reprodutivo}

Os acasalamentos ocorreram ao longo de todo o ano. Após serem inseminadas, não havendo resultado positivo de prenhez, efetuava-se o exame ginecológico e, segundo o caso, procedia-se ao tratamento indicado, visando uma inseminação posterior, monta natural ou descarte do animal. 
BORGES, D.P. et al. Desempenho produtivo e reprodutivo de um rebanho Guzerá leiteiro.

PUBVET, Londrina, V. 5, N. 4, Ed. 151, Art. 1017, 2011.

\subsection{Manejo Sanitário}

Ao nascer, fazia-se o corte e a desinfecção do umbigo do animal com uma solução de iodo a $10 \%$ durante três dias consecutivos.

As vermifugações eram realizadas conforme infestação. Já as vacinações foram realizadas as seguintes: contra febre aftosa, brucelose, clostridioses e leptospirose.

\subsection{Descrição das Características Estudadas}

A idade a primeira concepção foi estimada pela diferença entre a data do nascimento da matriz e a data do seu primeiro serviço, em dias. A idade ao primeiro parto foi obtida pela diferença entre a data do nascimento da matriz e a data da primeira parição, em dias. O intervalo de partos foi estimado pela diferença entre as datas de dois partos consecutivos, em dias. O período de gestação foi avaliado pela diferença, em dias, entre a data do último serviço que resultou em prenhez e a data do parto. O período de serviço foi estimado pela diferença entre as datas do parto e da próxima concepção que resultou em prenhez. O número de serviço por concepção foi obtido pelo número de inseminações por prenhez.

A duração da lactação foi calculada, em dias, pela diferença entre a data do parto e a data da secagem da matriz. O período de descanso do úbere foi estimado pela diferença entre as datas de secagem da matriz e a data do parto. A produção de leite por lactação foi estimada pelo controle leiteiro implantado na propriedade. A produção de leite por dia foi estimada dividindo-se a produção de leite total pelo número de dias de lactação.

$O$ peso ao nascer foi obtido pela pesagem do bezerro (machos e fêmeas) ao nascimento. A mortalidade de bezerros foi estimada pela relação entre o número de bezerros mortos e o número total de bezerros nascidos, multiplicado por 100 . 
BORGES, D.P. et al. Desempenho produtivo e reprodutivo de um rebanho Guzerá leiteiro.

PUBVET, Londrina, V. 5, N. 4, Ed. 151, Art. 1017, 2011.

\subsection{Análise Estatística}

Com base nas informações geradas por meio do controle zootécnico manual adotado na propriedade foi criado um banco de dados pelo programa Microsoft Excel ${ }^{\circledR}$ (1997). A consistência e o processamento dos dados foram realizados pelo mesmo programa. Calculou-se o número de observações, média, desvio padrão e coeficiente de variação para cada característica avaliada.

\section{RESULTADOS E DISCUSSÃO}

Os resultados obtidos para as características analisadas estão apresentados na Tabela 3.

Tabela 3 - Número de observações $(N)$, médias \pm desvios padrão $(\bar{x} \pm \mathrm{s})$, coeficientes de variação (CV), envolvendo as características analisadas.

\begin{tabular}{lccc}
\hline CARACTERÍSTICAS & $\mathrm{N}$ & $(\bar{x} \pm \mathrm{s})$ & $\mathrm{CV}$ \\
\hline IPF (dias) & 62 & $1119,39 \pm 237,09$ & 0,21 \\
IPP (dias) & 61 & $1403,85 \pm 249,48$ & 0,18 \\
IP (dias) & 148 & $470,89 \pm 100,31$ & 0,21 \\
PG (dias) & 212 & $283,21 \pm 7,05$ & 0,02 \\
DL (dias) & 139 & $259,46 \pm 50,50$ & 0,19 \\
PS (dias) & 151 & $188,77 \pm 117,11$ & 0,62 \\
PDU (dias) & 131 & $241,04 \pm 117,33$ & 0,49 \\
PL/LAC (kg) & 109 & $1416,07 \pm 660,13$ & 0,47 \\
PL/DIA (kg) & 101 & $5,46 \pm 2,34$ & 0,43 \\
PN (kg) & 208 & $32,42 \pm 3,18$ & 0,10 \\
\hline
\end{tabular}

Nota: IPF=idade à primeira concepção. IPP=idade ao primeiro parto. IP=intervalo de partos. $P G=$ período de gestação. $\mathrm{DL}=$ duração de lactação. PS=período de serviço. PDU=período de descanso do úbere. PL/LAC=Produção de leite por lactação. PL/DIA=Produção de leite por dia. $\mathrm{PN}=$ peso ao nascer. 
BORGES, D.P. et al. Desempenho produtivo e reprodutivo de um rebanho Guzerá leiteiro. PUBVET, Londrina, V. 5, N. 4, Ed. 151, Art. 1017, 2011.

A idade a primeira concepção apresentou média de 1119,39 dias (37,30 meses) com desvio padrão de 237,09 dias (7,90 meses), e coeficiente de variação de $21 \%$, em 62 registros processados (Tabela 3 ). Este valor mostra idade à primeira concepção tardia e superior ao encontrado por Balieiro (1976) de 33,70 $\pm 9,30$ meses. A idade ao primeiro parto apresentou média de 1403,85 dias ( 46,79 meses), com desvio padrão de 249,48 dias (8,31meses) e coeficiente de variação de $18 \%$, em 61 registros analisados. Este valor foi semelhante ao valor máximo $(47,00$ meses) apresentado na Tabela 1 revelando-se tardia, visto ser decorrente da elevada idade à primeira concepção refletindo na eficiência reprodutiva e produtiva e, conseqüentemente, na lucratividade da exploração.

Maior atenção às possíveis causas de elevação da idade à primeira concepção e ao primeiro parto como a observação inadequada de estros, desenvolvimento tardio do trato reprodutivo, deficiências no manejo nutricional, profilático-sanitário e, reprodutivo, habilidade não comprovada do inseminador, problemas com a qualidade do sêmen utilizado, entre outras, pode contribuir para redução das mesmas, revertendo em benefício de uma melhor eficiência reprodutiva e rendimento econômico da atividade.

O período de gestação apresentou média de 283,21 dias (9,44 meses), com desvio padrão de 7,05 dias (0,24 mês) e coeficiente de variação de $2 \%$, em 212 observações analisadas. Este valor foi inferior ao encontrado por Villares et al. (1949) que constataram 291,90 \pm 7,70 dias em vacas Guzerá.

O período de serviço apresentou média de 188,77 dias (6,30 meses) com desvio padrão de 117,11 dias (3,90 meses) e coeficiente de variação de $62 \%$, em 151 registros analisados. Este valor foi superior ao encontrado por Rangel et al. (2009) de 150,81 dias e por Bacalhau et al. (1994) de 122,00 dias. Vale ressaltar que no presente trabalho constatou-se um porcentual de período de serviço superior a 110 dias de $70 \%$. É fundamental identificar os prováveis fatores que contribuíram para um período de serviço elevado. Isto porque sua redução induz diretamente na redução do intervalo de partos, com reflexos evidentes na lucratividade da exploração. Entre os fatores 
BORGES, D.P. et al. Desempenho produtivo e reprodutivo de um rebanho Guzerá leiteiro. PUBVET, Londrina, V. 5, N. 4, Ed. 151, Art. 1017, 2011.

devem-se considerar os de natureza nutricional, sanitário, habilidade do inseminador, eficiência na detecção do estro. Para isto é necessária uma integração entre os aspectos fisiológicos, nutricionais e de manejo.

O intervalo de partos apresentou média de 470,89 dias (15,70 meses), com desvio padrão de 100,31 dias (3,34 meses) e coeficiente de variação de $21 \%$, em 148 registros analisados. Este resultado encontra-se entre aqueles apresentados na Tabela 2 que oscilaram entre 424,93 a 579,44 dias. Ressalta-se que foi constatada uma porcentagem de $74,32 \%$ de intervalo de partos superior a 390 dias, confirmando um percentual elevado para esta característica. Pode-se conjeturar que intervalos de partos mais curtos poderiam ser alcançados com a adoção de medidas que induzam à redução do período de serviço, o qual se revelou elevado no rebanho. Dentre estas medidas destacam-se o fornecimento de alimentação adequada nos períodos pré e pós-parto, cuidados sanitários e profiláticos visando controle de doenças relacionadas com a reprodução e detecção mais acurada de estros.

A duração da lactação apresentou média de 259,46 dias ( 8,65 meses), com desvio padrão de 50,50 dias (1,68 meses) e coeficiente de variação de 19\%, em 139 registros analisados. Este valor foi inferior aos encontrados por Barbosa e Pereira (1983) de 272,00 dias e por Bacalhau et al. (1994) de 273,00 dias, no entanto foi superior ao constatado por Bacalhau et al. (1990) de 167,80 dias.

O período de descanso do úbere apresentou média de 241,04 dias (8,03 meses), com desvio padrão de 117,33 dias (3,91 meses) e coeficiente de 49\%, em 131 observações processadas. A média encontrada neste trabalho foi muito alta extrapolando a recomendada na literatura, ou seja, em torno de 60 dias como forma de maximizar a produção na vida útil da vaca.

A produção de leite/lactação apresentou média de $1416,07 \mathrm{~kg}$ e desvio padrão de 660,13 kg, com coeficiente de variação de 47\%, em 109 registros analisados. Esta média foi inferior às citadas por Cobuci et al. (2000) e por Bacalhau et al. (1994) de, respectivamente, 2359,00 kg e 
BORGES, D.P. et al. Desempenho produtivo e reprodutivo de um rebanho Guzerá leiteiro.

PUBVET, Londrina, V. 5, N. 4, Ed. 151, Art. 1017, 2011.

$2314,00 \mathrm{~kg}$. Salienta-se que a produção de leite/dia neste estudo apresentou média de $5,46 \mathrm{~kg}$, com desvio padrão de $2,34 \mathrm{~kg}$ e coeficiente de variação de $43 \%$, em 101 registros processados.

O peso ao nascer apresentou média de $32,42 \mathrm{~kg}$, com desvio padrão de $3,18 \mathrm{~kg}$ e coeficiente de variação de $10 \%$, em 208 registros avaliados. Este valor foi superior aos encontrados por Bacalhau et al. (1992) de 31,76 $\mathrm{kg}$ e por Pelicioni et al. (2003) de 29,74 kg.

O número de serviço por concepção apresentou média de 1,73 . Este resultado segundo a classificação citada por Rawson (1986) foi desejável, embora as metas visem atingir média de 1,4 a 1,6 serviços/concepção. Dessa forma, deve-se atuar em medidas que possam reduzí-lo, como aquelas relacionadas com a eficiência na detecção do estro, habilidade do inseminador e qualidade do sêmen.

A porcentagem de mortalidade de bezerros durante a fase de aleitamento foi de 2,34\%. Este valor insere-se perfeitamente dentro dos percentuais admitidos por Pereira (2008) para a mortalidade média de bezerros durante esta fase, ou seja, de $15 \%$.

\section{CONCLUSÕES}

As idades médias à primeira concepção e ao primeiro parto mostraram-se tardias em função de práticas inadequadas de manejo nutricional e reprodutivo adotadas. Adicionalmente, a imprecisão na detecção de estros pode ter contribuído para o retardamento destas idades.

o período médio de gestação mostrou-se dentro do normalmente esperado visto ser uma característica quantitativa fenotipicamente pouco variável.

O período de serviço médio mostrou-se acima do considerado ideal para se obter intervalo médio entre partos em torno de doze meses. 
BORGES, D.P. et al. Desempenho produtivo e reprodutivo de um rebanho Guzerá leiteiro. PUBVET, Londrina, V. 5, N. 4, Ed. 151, Art. 1017, 2011.

O intervalo médio entre partos mostrou-se comprometido pela duração elevada do período de serviço, em parte, provavelmente, por imprecisão na detecção de estros.

O período médio de descanso do úbere mostrou-se muito acima do normalmente recomendado a uma eficiente exploração leiteira.

A duração média da lactação mostrou-se dentro de valores normalmente citados na literatura.

A média de produção de leite por lactação mostrou-se aquém das citadas na literatura consultada.

$\mathrm{O}$ peso ao nascer, a porcentagem de mortalidade de bezerros e o número de serviços por concepção mostraram-se favoráveis de acordo com a literatura consultada.

\section{REFERÊNCIAS}

ANDRADE, V.J. Manejo reprodutivo de fêmeas bovinas de corte. SIMPÓSIO DE PRODUÇÃO DE GADO DE CORTE, 1,1999, Viçosa - MG. Anais... Viçosa, p.85-135, 1999.

BACALHAU, A. S.; MARINHO, J. S.; ALBUQUERQUE, R. P. F. Produção de leite e período de lactação de vacas Gir e Guzerá. Juiz de Fora. EMBRAPA. p. 1-3 (Comunicado técnico, 09), 1990.

BACALHAU, A. S.; ALBUQUERQUE, R. P. F.; MARINHO, J. S.; SANTOS, E. S. Correlação entre peso ao nascer, idade e peso ao início da ruminação em bezerros Zebu. Pesquisa Agropecuária Brasileira, Brasília, v.27, n.11, p.1527-1532, 1992.

BACALHAU, A.S.; SANTOS, E.S.; ALBUQUERQUE, R.P.F. Influência da amamentação no desempenho reprodutivo e produtivo de vacas Zebu. Pesquisa Agropecuária Brasileira, Brasília, v.29, n.12, p.1995-2005, 1994.

BARBOSA, S.B.P., PEREIRA, C.S. Duração do período de lactação em rebanho Guzerá. In: REUNIÃO ANUAL DA SOCIEDADE BRASILEIRA DE ZOOTECNIA, 20, 1983. Pelotas, RS.

Anais... Pelotas, 1983.

COBUCI, J. A.; EUCLYDES, R. F.; VERNEQUE, R. S.; TEODORO, R. L.; LOPES, P.S.; SILVA, M. A. Curva de lactação na raça Guzerá. Revista Brasileira de Zootecnia, Viçosa, v.29, n. 5, Sept. /Oct. de 2000.

CORRÊA, D.M.; SANTOS, E.R. dos; CARVALHO, E.R. de. O início do período chuvoso em Uberlândia (MG): Um estudo dos últimos 14 anos. In: CONGRESSO BRASILEIRO DE GEOGRÁFOS, 6., 2004, Goiânia. Anais...

FERREIRA, F.; CAMPOS, W.E.; CARVALHO, A.U.; PIRES, M.F.A.; MARTINEZ, M.L.; SILVA, M.V.G.B.; VERNEQUE, R.S.; SILVA, P.F. Taxa de sudação e parâmetros histológicos de 
BORGES, D.P. et al. Desempenho produtivo e reprodutivo de um rebanho Guzerá leiteiro. PUBVET, Londrina, V. 5, N. 4, Ed. 151, Art. 1017, 2011.

bovinos submetidos ao estresse calórico. Arquivo Brasileiro Medicina Veterinária e Zootecnia, Belo Horizonte, v.61, n4, p.213-234, agosto, 2009.

FONSECA, V.O. O touro no contexto da eficiência reprodutiva do rebanho. Informe Agropecuário, Belo Horizonte, v. 21, n.205, p.48-63, 2000.

GRESSLER, S.L. Estudo de fatores de ambiente e parâmetros genéticos de algumas características reprodutivas em animais da raça Nelore. 149 f. Dissertação (Mestrado em Zootecnia) - Universidade Federal de Minas Gerais, Belo Horizonte, 1998.

GUIMARÃES, J.D.; ALVES, N.G.; DA COSTA, E. P.; SILVA, M.R.; COSTA, F.M.J.; ZAMPERLINI, B. Eficiências reprodutiva e produtiva de vacas da raça Gir, Holandês e cruzadas Holândes-Zebu. Revista Brasileira de Zootecnia, Viçosa, v.31, n.2, p.641-647, 2002.

KRUG, E. E. B.; SCHWERZ, E. V.; KRABBE, H.; DUPONT, L.; MONTARDO, O. V.; FAN, P. A.; FAVRETTO, D. Manual da produção leiteria. Cooperativa Central Gaúcha de Leite LTDA. 215p. 1980.

LÔBO, R. B. Programa de Melhoramento Genético da Raça Nelore. Ribeirão Preto-SP, 1996.104p.

LÔBO, R.N.B.A. A importância da escrituração zootécnica para o desenvolvimento da caprino-ovinocultura. Disponível em: www.cnpc.embrapa.br/genecoc/escrit.htm. Acesso em: 01 de junho de 2010.

MARQUES, J.R.F. Criação de gado leiteiro na Zona Bragantina. [Coronel Pacheco]: Embrapa, 2005. (Embrapa Amazônia Oriental, Sistemas de produção, 02). Disponível em: < http://sistemasdeproducao.cnptia.embrapa.br/FontesHTML/Leite/GadoLeiteiroZonaBraganti na/index.htm >. Acesso em abril, 2010.

MICROSOFT. Microsoft ${ }^{\circledR}$ Corporation Advanced Software, Inc. Santa Rosa, 1997.

O GUZERÁ. Disponível em: <http:// www.abcz.org.br/raças/guz.htm>. Acesso em 11 de março 2010.

PELICIONI, L. C.; QUEIROZ, S. A.; ALBUQUERQUE, L.G. Estimativas de parâmetros genéticos para pesos ao nascer e mensais até 450 dias em bovinos Guzerá. Archivos Latinoamericanos de Producción Animal, Mayaguez, v.11, n.1, p. 34-39, 2003. PEREIRA, J.C.C. Melhoramento genético das raças Zebus. In: __ Melhoramento genético aplicado à produção animal. Belo Horizonte: FEPMVZ, 2008. Cap. 14, p. 329387.

RANGEL, A. H. DO N.; BRAGA, A. P.; LIMA JÚNIOR, D. M. de; LIMA, R. N. de; ARAúJO, C. G. F. Influência de Fatores de Meio Ambiente sobre o Intervalo entre Partos de Rebanhos da Raça Jersey. Revista Verde, Mossoró, v.3, n.4, p. 42-45, 2008.

RANGEL, A. H. DO N.; GUEDES, P. L. C.; ALBUQUERQUE, R. P. F.; NOVAIS, L.P. Intervalo entre Partos e período de serviço de vacas Guzerá. Revista Verde, Mossoró, v.4, n.3, p. 21-25, 2009.

RAWSON, C.L.; MORROW, D.A. Reproductive management of small dairy farms. In: Current therapy in theriogenology. Philadelphia, PA: W. B. Saunders Company, 1986. 1143p., p.390-394. 
BORGES, D.P. et al. Desempenho produtivo e reprodutivo de um rebanho Guzerá leiteiro. PUBVET, Londrina, V. 5, N. 4, Ed. 151, Art. 1017, 2011.

RODRIGUES, A.A.; CRUZ, G.M. Comportamento social dos bovinos e o uso do espaço. [São Carlos, SP]: Embrapa, 2003.

VILLARES, J.B.; ABREU, J. Contribuição para o programa genético nas raças Gir, Indubrasil, Guzerá e Nelore. Boletim da Indústria Animal, Botucatu, v.10, p.30-40, 1949. 